\title{
A MULTI-VALUED DIAGNOSTIC MODEL SYNTHESIS BASED ON DESCRETE WAVELET TRANSFORM
}

\section{TWORZENIE WIELOWARTOŚCIOWEGO MODELU DIAGNOSTYCZNEGO Z WYKORZYSTANIEM DYSKRETNEJ TRANSFORMATY FALKOWEJ}

\author{
Henryk Borowczyk \\ Instytut Techniczny Wojsk Lotniczych \\ e-mail: borowczyk@post.pl
}

\begin{abstract}
The method of a multi-valued diagnostic model synthesis using discrete wavelet transform is presented. The method's algorithm consists of three stages: (1) - signal decomposition into low- and high frequency parts - approximations and details, (2) - approximations and details parameterization, (3) - multi-valued encoding parameters obtained in stage 2. The method is illustrated with vibroacoustic signal in real life experiment. The multi-valued diagnostic model is the final result.
\end{abstract}

Keywords: multi-valued diagnostic model, discrete wavelet transform, signal parameterization

Streszczenie: $W$ pracy przedstawiono metode tworzenia wielowartościowego modelu diagnostycznego $z$ wykorzystaniem dyskretnej transformaty falkowej. Algorytm metody składa się z trzech etapów: (1) - dekompozycja sygnału na składowe nisko- $i$ wysokoczęstotliwościowe (aproksymacje $i$ detale), (2) wyznaczenie parametrów (charakterystyk statystycznych) aproksymacji i detali, (3) - przeprowadzenie wielowartościowego kodowania wyznaczonych parametrów. Rozważania przeprowadzono na przykladzie sygnatu wibroakustycznego mierzonego podczas eksperymentu na obiekcie rzeczywistym. Końcowy rezultat przedstawiono $w$ postaci wielowartościowego modelu diagnostycznego.

Stowa kluczowe: wielowartościowy model diagnostyczny, dyskretna transformata falkowa, parametryzacja sygnatów 


\section{Wstęp}

W diagnostyce wibroakustycznej maszyn wirnikowych analizowane są sygnały poliharmoniczne $[1,4,5,6,9]$. W celu wyodrębnienia informacji o procesach dynamicznych związanych $\mathrm{z}$ funkcjonowaniem obiektu oraz oddziaływaniem uszkodzeń, sygnały poddawane są transformacjom do dziedziny częstotliwości [5, 6]. Wykorzystuje się głównie transformatę Fouriera (w tym krótkoczasową) oraz falkową, która umożliwia jednoczesną analizę sygnału w dziedzinie czasu i częstotliwości $[1,7]$.

Informacja niezbędna $\mathrm{w}$ procesie diagnozowania pozyskiwana jest $\mathrm{w}$ wyniku czynnych i biernych eksperymentów przeprowadzanych na obiekcie rzeczywistym, badań laboratoryjnych i na modelach symulacyjnych oraz kwerend wiedzy ekspertów [1, 9, 10, 11, 12].

Charakter i zakres eksperymentów zależy od posiadanej informacji wstępnej, przewidywanego wykorzystania wyników badań oraz możliwości realizacyjnych technicznych i formalno-prawnych.

W pracy przedstawiono metodę syntezy wielowartościowego modelu diagnostycznego z wykorzystaniem wyników eksperymentu przeprowadzonego na obiekcie rzeczywistym [1] oraz dyskretnej transformaty falkowej [14].

\section{Eksperyment diagnostyczny}

W diagnostyce złożonych obiektów technicznych można wyróżnić następujące rodzaje eksperymentów:

- badawczy - określenie wartości symptomów $d_{r} \in D, r=1,2, \ldots, t$ dla znanych stanów obiektu $e_{i} \in E, i=1,2, \ldots, n$, co umożliwia zbudowanie modelu diagnostycznego - relacji między stanami a symptomami;

- operacyjny - określenie bieżących wartości symptomów, a następnie ustalenie aktualnego stanu obiektu $\mathrm{z}$ wykorzystaniem modelu diagnostycznego;

- zespolony - łączy cechy eksperymentu operacyjnego i badawczego.

Eksperyment badawczy $\operatorname{Wibr}_{B}(\bullet)$ może być przedstawiony w następującej postaci:

$$
W_{i b r}(z a k r)=\left\langle E_{B W i b r}(z a k r),\left\{Y_{B W i b r}(z a k r)\right\}\right\rangle
$$

gdzie:

- $E_{B W i b r}(z a k r)$ - zbiór wprowadzanych uszkodzeń elementów;

- $Y_{B W i b r}(z a k r)$ - zbiór drganiowych sygnałów diagnostycznych;

- zakr - zakres pracy obiektu. 
Realizacja eksperymentu badawczego na obiekcie rzeczywistym w normalnych warunkach eksploatacji jest praktycznie niemożliwa. Badania o charakterze quasi-podstawowym, których celem jest określenie wpływu znanych uszkodzeń na przebiegi sygnałów drganiowych prowadzone są na specjalnie przygotowanych obiektach, $\mathrm{z}$ wykorzystaniem odpowiednich stanowisk laboratoryjnych. Ze względu na złożoność i duże koszty tego typu eksperymentów są one stosunkowo rzadkie.

Eksperyment operacyjny przeprowadza się na obiekcie rzeczywistym o nieznanym a'priori stanie technicznym.

$$
W i b r_{O}(z a k r)=\left\langle e_{\text {OWibr }}^{?}(z a k r), Y_{\text {OWibr }}(z a k r)\right\rangle
$$

Jeżeli uzyskane wyniki badań diagnostycznych można uzgodnić z posiadaną bazą wiedzy, tzn.:

$$
Y_{\text {OWibr }}(z a k r) \subseteq\left\{Y_{B W i b r}(z a k r)\right\}
$$

to określany jest bieżący stan obiektu

$$
e_{\text {OWibr }}^{?}(z a k r)=\left(e_{B W i b r}^{i}(z a k r) \in E_{B W i b r}(z a k r)\right)
$$

W przeciwnym przypadku, stan obiektu pozostaje nieznany i należy zastosować metodologię eksperymentu zespolonego.

Eksperyment zespolony składa się z dwóch faz: operacyjnej i badawczej, przy czym obligatoryjna jest faza operacyjna. Jeżeli symptomy z bieżącego badania diagnostycznego są zgodne $\mathrm{z}$ dotychczasową wiedzą - identyfikowany jest stan obiektu. W przeciwnym przypadku uruchamiana jest faza badawcza, w ramach której następuje aktualizacja wiedzy diagnostycznej z wykorzystaniem informacji z fazy operacyjnej, procesu odnowy, bezpośrednich metod oceny stanu (włącznie z kontrolnym demontażem) oraz badań symulacyjnych.

$\mathrm{W}$ niniejszej pracy rozpatrywany będzie eksperyment zespolony w diagnostyce wibroakustycznej, gdzie wykorzystuje się drgania i hałas jako nośniki informacji o stanie technicznym obiektów. Badania prowadzone są na ustalonych i/lub przejściowych zakresach pracy obiektu.

$$
W i b r_{Z}(z a k r)=\left\langle e_{\text {ZWibr }}^{*}(z a k r), Y_{\text {ZWibr }}(z a k r)\right\rangle
$$

Jeżeli spełniona jest zależność:

$$
Y_{Z W i b r}(z a k r) \subseteq\left\{Y_{B W i b r}(z a k r)\right\}
$$

to bieżący stan jest elementem zbioru znanych stanów:

$$
e_{\text {ZWibr }}^{*}(z a k r)=\left(e_{B W i b r}^{i}(z a k r) \in E_{B W i b r}(z a k r)\right)
$$


jeżeli nie - uruchamiana jest procedura aktualizacji bazy wiedzy:

$$
\begin{gathered}
\left\{Y_{B W i b r}(z a k r)\right\}^{\prime}=\left\{Y_{B W i b r}(z a k r)\right\} \cup Y_{\text {ZWibr }}(z a k r) \\
E_{B W i b r}^{\prime}(z a k r)=E_{B W i b r}(z a k r) \cup e_{Z W i b r}^{*}(z a k r)
\end{gathered}
$$

W rezultacie zwiększa się liczność zbióru uszkodzeń oraz zbioru realizacji sygnałów diagnostycznych zawartych w bazie wiedzy.

Przykładem jest eksperyment przeprowadzony w ramach projektu badawczego, który obejmował zagadnienia związane z kompleksowym diagnozowaniem układu łożyskowania turbinowego silnika śmigłowcowego Allison 250-C20B [ ].

\section{Parametryzacja sygnalów diagnostycznych}

Wynikiem badań diagnostycznych są zbiory pierwotnych sygnałów, które muszą być przetworzone do postaci umożliwiającej skuteczne wnioskowanie diagnostyczne $[1,10,11]$.

W celu zmniejszenia liczby danych wymagających analizy przeprowadza się parametryzację przebiegów czasowych polegającą na znalezieniu reprezentacji w postaci niewielkiego zbioru parametrów, przy zachowaniu informacji diagnostycznej niezbędnej w procesie wnioskowania $[1,2,7]$.

Operacja parametryzacji przeprowadzana jest $\mathrm{w}$ ustalonej ramie czasowozdarzeniowej, przy określonym zdarzeniu inicjującym i/lub chwili początkowej oraz zdarzeniu finalnym i/lub chwili końcowej.

Do sygnałów wibroakustycznych można zastosować jedną z poniższych metod:

- transformacje z dziedziny czasu do częstotliwości - transformata Fouriera,

- transformacja falkowa - łączna analiza czasowo-częstotliwościowa,

- wyznaczenie charakterystyk statystycznych sygnału (np. wartość średnia, odchylenie standardowe).

W niniejszej pracy parametryzację sygnałów wibroakustycznych przeprowadzono z wykorzystaniem dyskretnej transformaty falkowej [14]. Jej istota polega na rozłożeniu analizowanego sygnału na dwie składowe - niskoczęstotliwościową (tzw. aproksymacja) i wysokoczęstotliwościową (tzw. detale), a następnie wyznaczeniu macierzy współczynników falkowych dla przyjętego zbioru poziomów dekompozycji.

Na rys. 1 i 2 przedstawiono przykładowe wyniki dyskretnej transformacji falkowej sygnału drganiowego $\mathrm{s}$ [13] z wykorzystaniem, odpowiednio, falek db8 i sym8 [14] dla dwunastu poziomów dekompozycji. Lewa część okna zawiera zawiera wykres sygnału s i dwunastu aproksymacji niskoczęstotliwościowych (a1 - a12), natomiast prawa - obraz współczynników cfs, sygnału $\mathrm{s}$ i detali wysokoczęstotliwościowych d1 - d12. 
Szczegółowa analiza wskazuje na zależność wyników transformacji sygnału od rodzaju falki, zatem przed etapem syntezy modelu diagnostycznego należy podjąć decyzję odnośnie wyboru konkretnej falki (dalej wykorzystywana będzie falka db8).

W pierwszym przybliżeniu operację parametryzacji można przeprowadzić na podstawie charakterystyk statystycznych aproksymacji i detali. W tab. 1 przedstawiono obliczone wartości parametrów.

Symbolem aiA oznaczono i-ty parametr aproksymacji, natomiast aiD - i-ty parametr detalu. Jako parametry przyjęto:

- a1 - wartość średnia;

- a2 - mediana;

- a3 - wartość modalna;

- a4 - wartość maksymalna;

- a5 - wartość minimalna.

Analogiczne podejście można zastosować dla innych zbiorów parametrów opisujących aproksymacje, detale i współczynniki falkowe.

Tabela 1. Parametry aproksymacji $i$ detali dyskretnej transformaty falkowej sygnatu s (falka db8)

\begin{tabular}{|r|r|r|r|l|r|r|r|r|r|c|}
\hline Lp & \multicolumn{1}{c|}{ a1A } & \multicolumn{1}{c|}{ a2A } & \multicolumn{1}{c|}{ a3A } & \multicolumn{1}{l}{ a4A } & \multicolumn{1}{c|}{ a5A } & a1D & a2D & a3D & a4D & a5D \\
\hline 1 & 0,3 & 1,4 & 18,2 & 175,4 & $-202,0$ & 0,2 & $-0,5$ & 0,1 & 174,0 & $-162,7$ \\
\hline 2 & 0,4 & $-0,3$ & $-9,6$ & 177,8 & $-162,9$ & 0,2 & 0,5 & 24,6 & 166,4 & $-174,0$ \\
\hline 3 & 0,5 & $-1,7$ & 21,9 & 189,5 & $-135,0$ & 0,0 & $-2,6$ & $-17,5$ & 129,5 & $-122,6$ \\
\hline 4 & 1,0 & $-2,4$ & $-73,6$ & 167,5 & $-140,2$ & 0,5 & 0,1 & $-35,0$ & 113,3 & $-114,8$ \\
\hline 5 & 1,5 & 1,6 & $-106,6$ & 190,5 & $-173,3$ & 0,1 & $-0,6$ & $-7,7$ & 72,3 & $-73,0$ \\
\hline 6 & 3,0 & 9,8 & $-133,3$ & 227,3 & $-214,2$ & $-0,1$ & $-6,6$ & $-73,4$ & 129,3 & $-129,4$ \\
\hline 7 & 6,8 & 4,3 & $-20,5$ & 127,0 & $-39,9$ & $-2,3$ & $-2,4$ & 165,4 & 269,3 & $-297,3$ \\
\hline 8 & 16,1 & 3,5 & 1,7 & 153,9 & $-6,3$ & $-0,9$ & 0,0 & $-32,7$ & 81,2 & $-58,2$ \\
\hline 9 & 41,3 & 4,2 & 4,3 & 219,5 & 0,6 & $-0,6$ & $-0,5$ & 1,6 & 43,8 & $-17,9$ \\
\hline 10 & 110,7 & 7,2 & 6,3 & 315,6 & 1,1 & $-0,7$ & $-0,3$ & $-0,4$ & 45,7 & $-33,3$ \\
\hline 11 & 303,9 & 376,4 & 383,6 & 450,2 & 6,2 & $-2,3$ & $-3,0$ & $-8,6$ & 59,0 & $-56,9$ \\
\hline 12 & 529,9 & 532,4 & 504,0 & 544,2 & 503,3 & $-4,9$ & $-4,4$ & $-16,5$ & 73,2 & $-89,8$ \\
\hline
\end{tabular}


A multi-valued diagnostic model synthesis based on descrete wavelet transform Tworzenie wielowartościowego modelu diagnostycznego ...

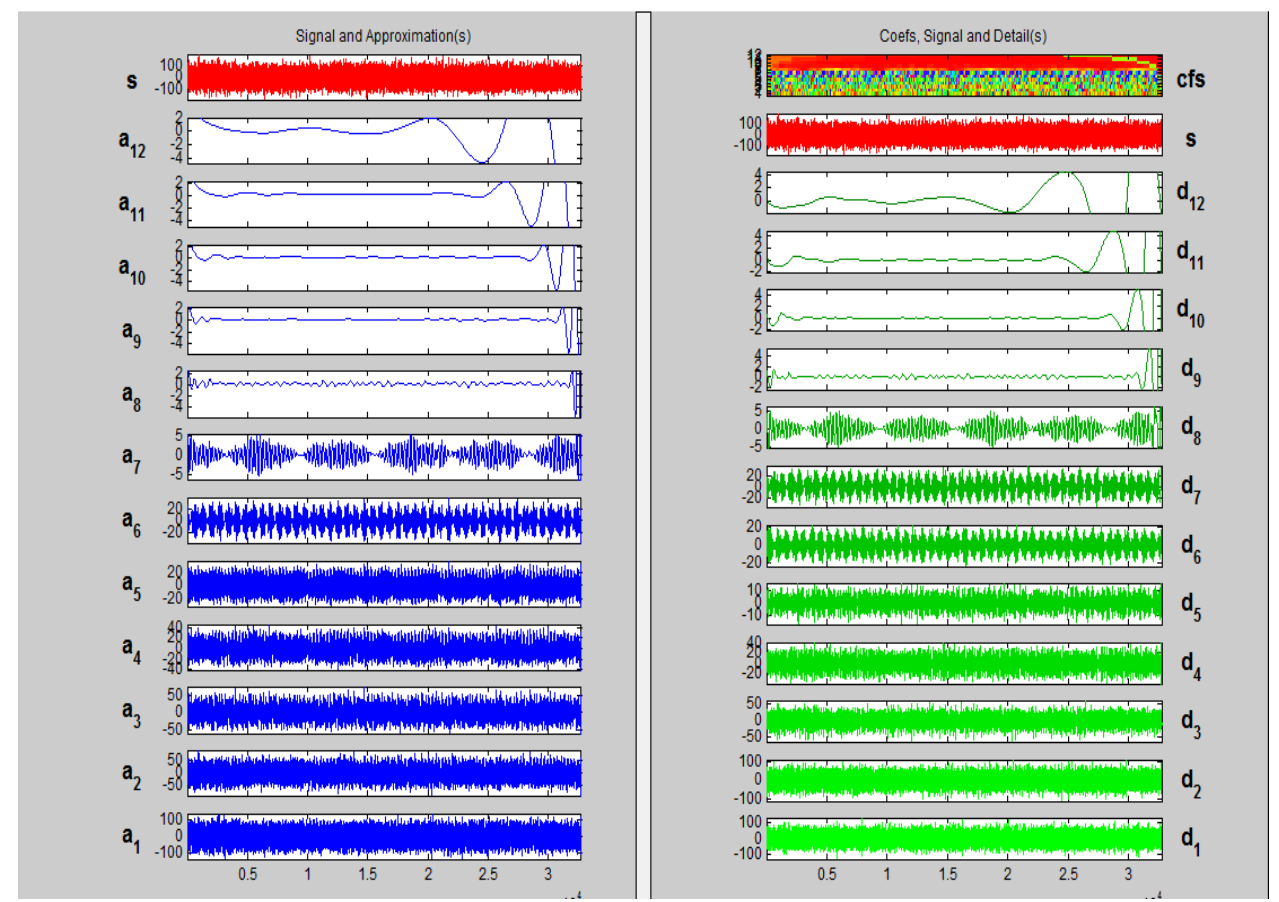

Rys. 1 Dyskretna transformata falkowa sygnatu s (falka db8)
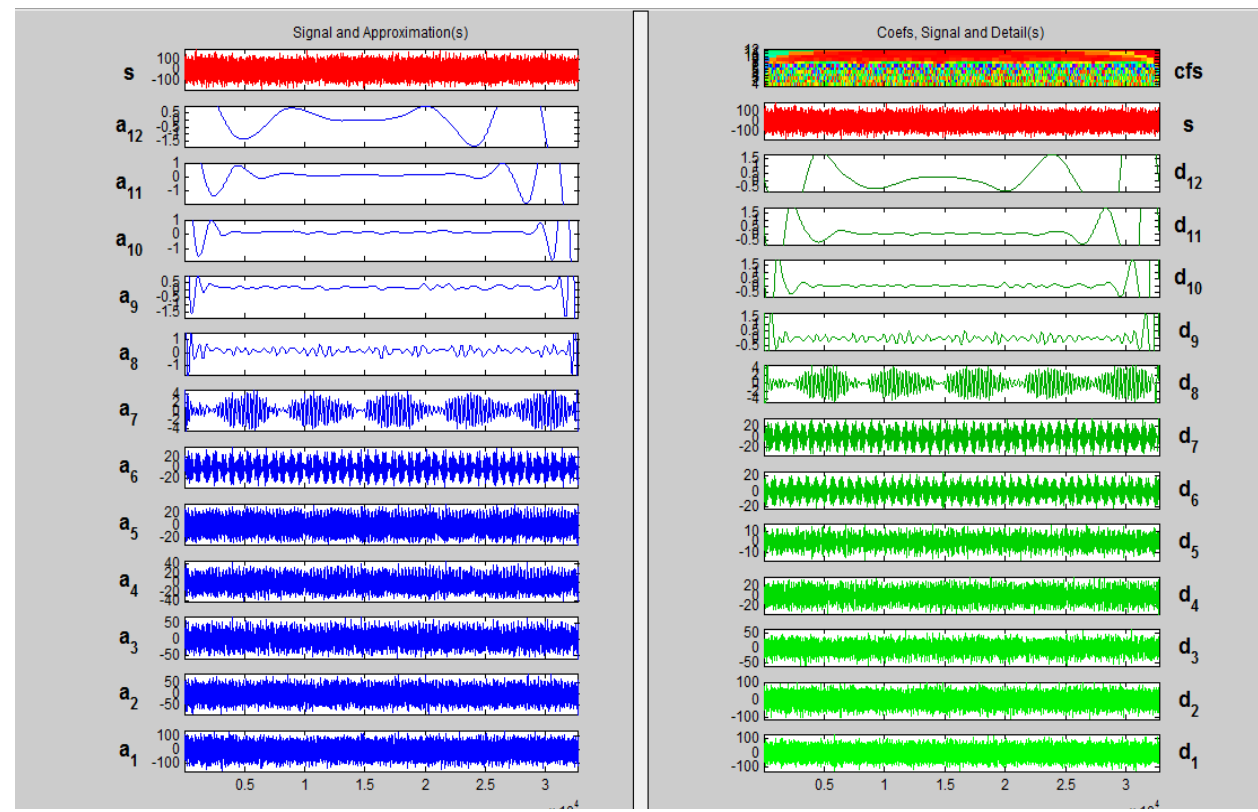

Rys. 2 Dyskretna transformata falkowa sygnatu s (falka sym8) 


\section{Kodowanie parametrów}

W wyniku zastosowania parametryzacji sygnałów otrzymuje się skończony zbiór parametrów diagnostycznych zawierający informację o stanie obiektu.

W procesie wnioskowania istotne są nie tyle dokładne wartości parametrów, ile ich przynależność do odpowiednich zakresów dających się zinterpretować w zbiorze klas stanu technicznego diagnozowanego obiektu [1, 2, 3,].

Zakresy zmienności parametrów diagnostycznych należy zatem podzielić na przedziały $\mathrm{w}$ taki sposób, aby $\mathrm{z}$ jednej strony zapewnić jak najwyższą rozdzielczość (rozróżnialność stanów/uszkodzeń), a z drugiej - zminimalizować liczbę błędnych diagnoz.

Kodowanie całkowitoliczbowe polega na przypisaniu wartościom parametrów z określonego przedziału liczb rzeczywistych jednej liczby całkowitej ze znakiem.

Zasada kodowania może być jednakowa dla wszystkich parametrów lub ustalana indywidualnie dla każdego z nich.

Oznaczając przez $X_{C}$ wartość kodową parametru $x$ uzyskaną w wyniku kodowania całkowitoliczbowego, ogólną zasadę kodowania można przedstawić w postaci (10).

$$
\begin{aligned}
& X_{C}=\left\{\begin{array}{lll}
\ldots & & \\
k-1 & d l a & x \in\left[x_{k-1}, x_{k}\right), k \leq K \\
\ldots & & \\
1 & d l a & x \in\left[x_{1}, x_{2}\right) \\
0 & d l a & x \in\left(x_{1_{-}}, x_{1}\right) \\
-1 & \text { dla } & x \in\left(x_{2_{-}}, x_{1_{-}}\right] \\
\ldots & & \\
-\left(k_{-}-1\right) d l a & x \in\left(x_{k_{-}}, x_{\left(k_{-}-1\right)}\right], k_{-} \leq K_{-} \\
\ldots & &
\end{array}\right. \\
& \text { gdzie: } \ldots<x_{k_{-}}<\ldots<x_{1_{-}}<x_{1} \ldots<x_{k}<\ldots
\end{aligned}
$$

Kod 0 przypisuje się przedziałowi wartości nominalnych $\left(x_{1}, x_{1}\right)$ parametru $x$ obiektu zdatnego lub przedziałowi centralnemu wyników eksperymentu. Drugie podejście stosuje się $\mathrm{w}$ przypadku eksperymentu zespolonego; gdzie przestrzeń stanów i wyników eksperymentu jest otwarta. Należy przy tym zauważyć, że liczby przedziałów/kodów poniżej i powyżej przedziału nominalnego $\left(K_{-}\right.$i $K$ ) nie muszą być jednakowe. 
Wyznaczanie progów $x_{k}, k=1,2, \ldots, K$ i $x_{k_{-}}, k_{-}=1,2, \ldots, K_{-}$można rozpatrywać jako zagadnienie formalne klasteryzacji danych lub heurystyczne. W pierwszym przybliżeniu najczęściej stosuje się podejście heurystyczne wykorzystujące wiedzę ekspercką i nie wymagające dużego zbioru danych statystycznych. W procesie rozwoju systemu diagnostycznego, po zgromadzeniu odpowiedniej ilości materiału eksperymentalnego, wstępnie wyznaczone progi poddawane są okresowej aktualizacji z zastosowaniem metod formalnych.

W przypadku eksperymentu badawczego, gdzie stan obiektu (w tym stan zdatności) jest znany, analizę należy rozpocząć od określenia przedziału nominalnych wartości rozpatrywanych parametrów. Kolejne progi ustala się w punktach istotnych zmian wartości parametrów uporządkowanych monotonicznie.

W eksperymencie zespolonym, którego wyniki opisuje rozkład Gaussa, przyjmuje się, że wartości parametrów z przedziału $(\mu-\sigma, \mu+\sigma)$, gdzie $\mu$ - wartość średnia, $\sigma$ - odchylenie standardowe, odpowiadają stanowi zdatności, natomiast przekraczające kolejne progi

$$
\begin{aligned}
& x_{k}=\mu+k \sigma, k=1, \ldots, K \\
& x_{k_{-}}=\mu-k \sigma, k_{-}=1, \ldots, K_{-}
\end{aligned}
$$

sygnalizują stany niepełnej zdatności lub niezdatności. W takim przypadku progi rozłożone są równomiernie i symetrycznie względem wartości średniej.

Tabela 2 zawiera wyniki całkowitoliczbowego kodowania parametrów przedstawionych w tab. 1 .

Tabela 2. Wielowartościowa reprezentacja parametrów aproksymacji i detali dyskretnej transformaty falkowej sygnatu s (falka db8)

\begin{tabular}{|c|c|c|c|c|c|c|c|c|c|c|}
\hline Lp & a1A & a2A & a3A & a4A & a5A & a1D & a2D & a3D & a4D & a5D \\
\hline 1 & -3 & 0 & 0 & -1 & -3 & 2 & -2 & 1 & 2 & -2 \\
\hline 2 & -3 & 0 & 0 & -1 & -2 & 2 & 1 & 2 & 2 & -2 \\
\hline 3 & -3 & 0 & 0 & 0 & -1 & 2 & -3 & -1 & 1 & -1 \\
\hline 4 & -3 & 0 & -2 & -1 & -1 & 3 & 1 & -2 & 0 & 0 \\
\hline 5 & -3 & 0 & -3 & 0 & -2 & 2 & -2 & 0 & -1 & 1 \\
\hline 6 & -3 & 0 & -3 & 0 & -3 & 1 & -3 & -2 & 1 & -1 \\
\hline 7 & -2 & 0 & 0 & -3 & 0 & -2 & -3 & 3 & 3 & -3 \\
\hline 8 & -1 & 0 & 0 & -2 & 1 & 0 & 1 & -2 & 0 & 2 \\
\hline 9 & 0 & 0 & 0 & 0 & 2 & 0 & -2 & 1 & -3 & 3 \\
\hline 10 & 1 & 0 & 0 & 1 & 2 & 0 & -2 & 0 & -3 & 3 \\
\hline 11 & 2 & 2 & 2 & 2 & 2 & -2 & -3 & 0 & -2 & 2 \\
\hline 12 & 3 & 3 & 3 & 3 & 3 & -3 & -3 & -1 & -1 & 0 \\
\hline
\end{tabular}


Po przeprowadzeniu kodowania parametrów otrzymuje się wielowartościowy model diagnostyczny (uogólnienie stosowanych powszechnie modeli binarnych) opisujący relacje między zbiorem uszkodzeń i zbiorem symptomów (kodowych wartości parametrów diagnostycznych).

Taka forma modelu jest dogodna do dalszych analiz, mających na celu wyznaczenie optymalnego zbioru symptomów zapewniającego rozróżnialność stanów z założoną dokładnością [3], a następnie zbioru reguł wnioskowania w ekspertowym systemie diagnostycznym $[2,7,8]$.

\section{Podsumowanie}

Przedstawiona metoda syntezy wielowartościowego modelu diagnostycznego z wykorzystaniem dyskretnej transformaty falkowej umożliwia istotne zmniejszenie ilości danych niezbędnych do przeprowadzenia wnioskowania diagnostycznego. Może być stosowana w różnych obszarach diagnostyki, gdzie wynikiem eksperymentu są przebiegi czasowe sygnałów.

Proponowane podejście umożliwia elastyczny rozwój modelu diagnostycznego w trakcie gromadzenia wiedzy w kolejnych eksperymentach (badawczych, operacyjnych i zespolonych).

\section{Literatura}

[1] Borowczyk H.. (red.) Problemy kompleksowego diagnozowania układu łożyskowania turbinowego silnika śmigłowcowego. Wyd. Instytutu Technicznego Wojsk Lotniczych. Warszawa 2011, 163 s.

[2] Borowczyk H.. Ekspertowy system wspomagania wnioskowania diagnostycznego. W: Borowczyk H.. (red.) Problemy kompleksowego diagnozowania układu łożyskowania turbinowego silnika śmigłowcowego. Wyd. Instytutu Technicznego Wojsk Lotniczych. Warszawa 2011, s. 147-163

[3] Borowczyk H.: Quasi-informacyjna metoda wyznaczania programu diagnozowania złożonych obiektów technicznych, rozprawa doktorska, WAT, Warszawa 1984.

[4] Borowczyk H., Lindstedt P., Magier J.: Układ łożyskowania turbinowego silnika śmigłowcowego jako obiekt diagnozowania. W : Borowczyk H.. (red.) Problemy kompleksowego diagnozowania układu łożyskowania turbinowego silnika śmigłowcowego. Wyd. Instytutu Technicznego Wojsk Lotniczych. Warszawa 2011, s. 21-30

[5] Cempel Cz.: Podstawy wibroakustycznej diagnostyki maszyn, WNT, Warszawa 1982.

[6] Cempel Cz.: Wibroakustyka stosowana, WNT, Warszawa 1989.

[7] Cholewa W.: Data processing and reasoning in technical diagnostics. Wyd. Naukowo-Techniczne, Warszawa, 1995. 
[8] Korbicz J. i in.: Diagnostyka procesów. Modele. Metody sztucznej inteligencji. Zastosowania. WNT, Warszawa 2002.

[9] Lindstedt P., Borowczyk H., Magier J.: Diagnostyka silnika śmigłowcowego w inżynieryjno-lotniczym otoczeniu, „Prace Naukowe ITWL”, zeszyt nr 17. Wyd. ITWL, Warszawa 2003.

[10] Lindstedt P., Borowczyk H.: Kompleksowy system diagnostyczny statku powietrznego, w: Problemy Badań i Eksploatacji Techniki Lotniczej, tom 4, rozdz. 7, Wyd. ITWL, Warszawa 1999.

[11] Lindstedt P.: Praktyczna diagnostyka maszyn i jej teoretyczne podstawy. Wyd. Naukowe ASKON, Warszawa 2002.

[12] Niziński S.: Elementy eksploatacji obiektów technicznych, Wydawnictwo Uniwersytetu Warmińsko-Mazurskiego, Olsztyn 2000.

[13] Spychała J., Szczekala M., Żokowski M.: Diagnozowanie w dziedzinie wibroakustycznej. W: Borowczyk H.. (red.) Problemy kompleksowego diagnozowania układu łożyskowania turbinowego silnika śmigłowcowego. Rozdz. 5. Wyd. Instytutu Technicznego Wojsk Lotniczych Warszawa 2011

[14] Wavelet toolbox. User's guide. Mathworks 2011

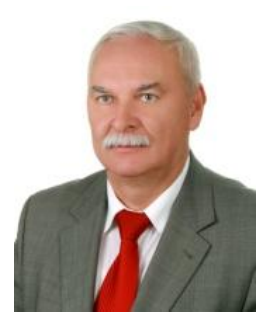

Dr inż. Henryk Borowczyk, Zakład Silników Lotniczych, Instytut Techniczny Wojsk Lotniczych, Warszawa. Działalność naukowobadawcza: kompleksowa diagnostyka lotniczych silników turbinowych $z$ wykorzystaniem teorii informacji, metod identyfikacji matematycznych modeli układów dynamicznych i sztucznej inteligencji. 